\title{
Caracterização microbiológica e físico-química de águas superficiais em parques urbanos no Distrito Federal
}

\author{
Milene Rocha Ribeiro ${ }^{1}$ \\ Simone Rodrigues Sousa ${ }^{2}$ \\ Daphne Heloisa de Freitas Muniz ${ }^{3}$ \\ Maria Claudia da Silva ${ }^{4}$ \\ Eduardo Cyrino Oliveira-Filho ${ }^{5}$
}

\section{Resumo}

Ambientes hídricos localizados em centros urbanos sofrem intensas pressões das atividades antrópicas, comprometendo sua qualidade. A criação de parques urbanos constitui uma das principais estratégias para minimizar esses impactos. Este trabalho objetivou caracterizar parâmetros microbiológicos e físico-químicos de águas localizadas em quatro parques urbanos no DF, que fazem parte da unidade hidrográfica do Lago Paranoá. As coletas ocorreram mensalmente nos períodos de outubro a dezembro de 2009 e março a maio de 2010. Os resultados mostram três parques (Parques Águas Claras, Parque Asa Sul e Parque Olhos D’́gua) que apresentaram coliformes termotolerantes em concentrações crescentes nos meses de outubro a dezembro (entre 200 e 2.419,60 NMP/100 mL) e valores decrescentes em março a maio (de 2.419,60 a 344,60 NMP/100 mL). Já no Parque Ezechias Heringer (Guará), a partir de dezembro, o quantitativo permaneceu constante com valor $>2.419,6 \mathrm{NMP} / 100 \mathrm{~mL}$. Os parâmetros físico-químicos não apresentaram variações significativas ao longo dos meses, mas foram expressivos na avaliação da qualidade da água do Parque Asa Sul.

Palavras-chave: Qualidade de água. Poluição. Urbanização.

\footnotetext{
1 Graduação Biologia, UniCEUB, email: millaspdf@gmail.com.

Graduação Engenharia Ambiental, Universidade Católica de Brasília -UCB.

3 Graduação em Química, Embrapa Cerrados

4 Professora do Centro Universitário de Brasília - UniCEUB.

5 Professor do UniCEUB e Pesquisador da Embrapa Cerrados.
} 


\section{Introdução}

Ambientes hídricos localizados em centros urbanos podem sofrer intensas pressões das atividades antrópicas comprometendo sua qualidade. A criação de parques urbanos constitui uma das principais estratégias utilizadas para minimizar esses impactos e atingir conservação de ambientes naturais.

Os parques do Distrito Federal são disciplinados de acordo com os dispositivos da Lei Complementar n 265 de 1999, que os classifica em Parques Ecológicos e Parques de Uso Múltiplo, e são considerados unidades de uso sustentável. Dentre essa classificação, os Parques Ecológicos devem possuir áreas de preservação permanente, nascentes, olhos d'água, veredas, matas ciliares, campos de murunduns ou manchas representativas de qualquer fitofisionomia do cerrado que abranjam, no mínimo, trinta por cento da área total da unidade. Já os Parques de Uso Múltiplo devem situar-se dentro de centros urbanos, ou contíguos a eles em áreas de fácil acesso à população, predominantemente coberta por vegetação nativa ou exótica. Sendo ainda necessário possuir infraestrutura para o desenvolvimento de atividades recreativas, culturais, esportivas, educacionais e artísticas (CÂMARA LEGISLATIVA DO DISTRITO FEDERAL, 1999).

Nos centros urbanos, a deterioração da qualidade da água é quase inevitável. O gerenciamento inadequado da drenagem urbana, a falta de coleta e disposição do lixo, resulta em uma forte degradação do meio aquático localizado nessas regiões (TUCCI, 2000). A atividade construtiva pode multiplicar de 50 até 100 vezes a sedimentação e a carga de solutos, elevando as concentrações químicas bem como o conteúdo orgânico dos rios (DREW, 1999).

Rondon Lima (2001) diferencia as variedades de poluentes lançados nos corpos d'água como: pontuais, provenientes de resíduos industriais e domésticos, e difusos, resultantes do escoamento em áreas urbanas e rurais que ocorrem durante os períodos de chuva. Dessa forma, os rios funcionam como coletores naturais das paisagens, refletindo o uso e ocupação do solo de sua respectiva bacia de drenagem.

A qualidade da água está relacionada com interferências antrópicas, e os principais impactos gerados em função das atividades humanas são o assoreamen- 
to e homogeneização do leito de rios e córregos, diminuição da diversidade de habitats e microhabitats e eutrofização artificial (GOULAR; CASTILO, 2003).

Os resíduos provenientes das atividades humanas causam danos ao ecossistema natural e às comunidades aquáticas envolvidas e atingem o próprio homem por meio dos malefícios associados à salubridade ambiental e ao comprometimento da qualidade da água (BOLLMANN, 2003). Para Libano (2004), a contaminação de águas naturais representa um dos principais problemas de saúde pública. Ele verificou que estados com os piores indicadores sociais (IDH $>0,6)$ apresentam menores índices de rede sanitária $(<50 \%)$.

Outra preocupação é a forma como as ampliações dos espaços urbanos têm ocorrido, sem cuidados com a preservação ambiental e a destruição das matas ciliares, comprometendo a perenidade dos rios (RIBEIRO; SCHIAVINI, 1998). Aliadas a isso, as taxas de crescimento da produção agrícola mundial, superadas pelas dos incrementos populacionais, fizeram aumentar a demanda e a preocupação com a quantidade e a qualidade dos recursos hídricos (PAZ; TEODORO; MENDONÇA, 2000).

Portanto, o estudo da qualidade da água tornou-se fundamental para avaliar as possibilidades de uso, entre as quais estão: proteção da diversidade biológica, atividades recreativas, aspectos culturais, beleza cênica e consumo humano, entre outras (STRIEDER et al. 2006). Além disso, os recursos hídricos são limitados e têm um papel significativo no desenvolvimento econômico e social de uma região. Assim, fazem-se necessárias pesquisas que levantem informações sobre a qualidade dos recursos hídricos e sua conservação.

O bioma Cerrado, em especial, ocupa um espaço geográfico que desempenha um papel fundamental no processo de distribuição dos recursos hídricos pelo país, sendo local de origem das grandes bacias hidrográficas brasileiras e do continente sul americano (LIMA; SILVA, 2008). Dessa forma, pesquisas desenvolvidas no Cerrado revestem-se de grande relevância, pois poderão potencialmente trazer impactos diretos para quase todo o país. 
As águas em estudo pertencem à microbacia do Riacho Fundo, uma unidade hidrográfica do Lago Paranoá, pertencente à bacia hidrográfica do Rio São Bartolomeu que, por sua vez, faz parte da região hidrográfica do Rio Paraná (MOREIRA; BOAVENTURA, 2003). Essas águas abastecem o Lago Paranoá que representa um cartão postal para a cidade de Brasília, possuindo usos múltiplos como de valor cultural, beleza cênica, recreação e turismo.

Nesse contexto, o presente trabalho tem como objetivo caracterizar a qualidade da água superficial de quatro parques urbanos do Distrito Federal, por meio dos indicadores biológicos coliformes totais e termotolerantes e dos indicadores físico-químicos $\mathrm{pH}$, temperatura, oxigênio dissolvido (OD), condutividade (CT) e totais de sólidos dissolvidos (TDS).

\section{Material e métodos}

A pesquisa foi realizada em quatro parques do Distrito Federal: Parque Ecológico Águas Claras (P1), Parque Ecológico Ezechias Heringer (P2), Parque Ecológico e de Uso Múltiplo da Asa Sul (P3) e Parque Ecológico de Uso Múltiplo Olhos D’água (P4), localizados respectivamente nas regiões administrativas de Águas Claras, Guará e Brasília.

Os critérios estabelecidos para a escolha dos parques foram: a) parque urbano com a presença de mananciais e/ou córregos; e b) fazer parte da unidade hidrológica do Lago Paranoá. A escolha dos períodos de coleta foi determinada de acordo com a sazonalidade do clima na região do Cerrado, que apresenta período chuvoso, na maior parte da região, entre outubro e março (GOMES et al., 2004). Os períodos de chuvas podem influenciar nas concentrações de coliformes na água e contribuir com a mudança da qualidade microbiológica da água (CUNHA, 2001).

Para a análise microbiológica, foi utilizado o método dos substratos enzimáticos. Já as análises físico-químicas foram realizadas por meio de medidor portátil multiparâmetro. As coletas ocorreram entre os meses de outubro e dezembro de 2009 e entre março e maio de 2010, com frequência mensal. 
As amostras foram coletadas em recipientes transparentes, previamente esterilizados, e contendo tiossulfato de sódio. Esses foram etiquetados e acondicionados em caixas isotérmicas aproximadamente à $10^{\circ} \mathrm{C}$, levados ao Laboratório de Ecotoxicologia da Embrapa Cerrados e analisados em tempo não superior a quatro horas após a coleta. Todos os procedimentos de coleta e preservação de amostras e metodologias analíticas adotadas obedeceram aos critérios adotados pela Associação de Saúde Pública dos Estados Unidos (APHA, 1998).

\subsection{Determinações microbiológicas}

As determinações de coliformes totais e termotolerantes foram realizadas no Laboratório de Ecotoxicologia da Embrapa Cerrados, utilizando o método cromogênico (Colilert, da Idexx), como descrito no "Standard Methods for the Examination of Water and Westwater" (APHA, 1998). Esse método utiliza a tecnologia de substrato definido - "Defined Substrate Tecnology" (DST) - para detecção de coliformes totais e Escherichia coli em água (IDEXX, 2009). Esse método é recomendado para análise de coliformes somente em águas doce, mineral, de abastecimento e afluentes domésticos.

Em laboratório, adicionou-se em cada amostra (100 mL de água) a ampola de substrato, sendo agitado vigorosamente para sua completa dissolução. Em seguida, as amostras contendo substrato foram transferidas para a cartela Quanti-Tray ${ }^{\circledast} / 2000$ que foi selada. Estas foram incubadas em estufa a $35 \pm 0,5^{\circ} \mathrm{C}$ por exatamente 24 horas. Após esse período, realizou-se a leitura dos resultados.

Para as bactérias do grupo coliformes totais, foi utilizado o substrato cromogênico, ortho-nitrophenyl- $\beta$-D-galactopyranoside (ONPG), que detecta a enzima $\beta$-D-galactosidase. Esta hidrolisa o substrato e produz a mudança de cor, que indica positividade para coliformes totais em 24 horas.

Já para as bactérias termotolerantes E. coli, foi utilizado o substrato fluorogênico, 4-methylumbelliferyl- $\beta$-D-glucuronide (MUG), que detecta a enzima $\beta$-glucuronidase. Essa enzima hidrolisa o substrato e produz um produto fluores- 
cente quando visualizado em luz ultravioleta (UV) com comprimento de onda longo $(366 \mathrm{~nm})$. A presença da fluorescência indica positividade para E. coli.

\subsection{Determinações físico-químicas}

Os parâmetros $\mathrm{pH}$, temperatura, condutividade, total de sais dissolvidos (TDS), oxigênio dissolvido (OD) foram determinados nos pontos de coleta, utilizando o medidor portátil multiparâmetro HI 9828 da marca Hanna.

\subsection{Caracterização das áreas de estudo}

O Parque Ecológico Águas Claras (P1) foi criado pela Lei Complementar $\mathrm{n}^{\circ}$ 287 de abril de 2000 e está localizado na Região Administrativa de Águas Claras. Sua área abrange 96 hectares e, antes de sua criação, havia chácaras no local. Portanto, a vegetação nativa encontra-se alterada com predominância de vegetação exógena, espécies arbóreas frutíferas cultivadas, eucalipto e gramíneas invasoras. No parque estão localizadas quatro nascentes que formam o Córrego Águas Claras.

O Parque Ecológico Ezechias Heringer (P2), também conhecido como "Parque do Guará", existe desde a década de 60, mas somente em janeiro de 1998 foi sancionada a Lei ${ }^{\circ} 1.826$ que regulamenta sua criação. Localiza-se nas Áreas 27 e 28 da Região Administrativa do Guará, com área de 306,44 hectares. O parque foi criado principalmente para disciplinar a ocupação da área, garantir a preservação dos ecossistemas remanescentes e promover a recuperação de áreas degradadas com espécies vegetais nativas da região (IBRAM, 2009). A vegetação nativa inclui mata ciliar de ambas as margens e em áreas adjacentes ao Córrego do Guará. A mata de galeria encontra-se interrompida em diversos trechos, mas ainda compõe, em conjunto com as árvores exóticas plantadas na região, um bom maciço arbóreo. Esse parque cumpre um papel importante na região; tem função de corredor ecológico, pois está entre duas Unidades de Conservação: a Reserva Ecológica do Guará e o Santuário de Vida Silvestre do Riacho Fundo. 
O Parque Ecológico e de Uso Múltiplo Asa Sul (P3) foi implantado em setembro de 2003, com área de aproximadamente 22 hectares. Está localizado em Brasília e possui afloramentos de água que contribuem com a Bacia do Lago Paranoá. A vegetação predominante é a gramínea exógena Brachiara sp.

O Parque Ecológico e de Uso Múltiplo Olhos D’água (P4) foi criado pelo Decreto $\mathrm{n}^{\circ} 15.900$ de setembro de 1994 com área de 21 hectares, compreende as superquadras 413 e 414 e a área comercial 414/415 da Asa Norte. A característica principal do Parque é a presença do Córrego Talvegue que o atravessa de oeste para leste, e a existência de uma lagoa, abastecida por um "olho d'água" que deu origem ao nome do parque.

\section{Resultados}

A quantificação de coliformes totais obtida em todas as amostras foi > 2.419,60 NMP/100 mL. Os resultados das análises para o parâmetro coliformes termotolerantes estão apresentados na figura 1. As amostras de P1 variaram entre 816,40 e >2.419,60 NMP/100 mL; de P2 entre 1.046,20 e >2.419,60 NMP/100 $\mathrm{mL}$; de P3 entre 209,8 e 1.732,90 NMP/100 mL; e de P4 entre 613,10 e 2.419,60 $\mathrm{NMP} / 100 \mathrm{~mL}$.

Verificou-se que nos parques: Águas Claras (P1), Asa sul (P3) e Olhos D’água (P4), nos meses de outubro a dezembro, as amostras apresentaram um crescente número de coliformes termotolerantes e, de março a maio, o número decresceram. Observou-se que os maiores valores encontrados em todos os pontos ocorreram nos meses de dezembro e março, com exceção do Parque Ezechias Heringer (P2), que apresentou um número constante de coliformes termotolerantes nos meses de dezembro, março, abril e maio. De um modo geral, todos os parques apresentaram níveis de contaminação de coliformes termotolerantes altos. Com destaque em P2, que apresentou o maior índice de contaminação, seguidos por P1 e P4, sendo P3 o parque com o menor nível de contaminação fecal (Figura 1). 
Figura 1: Variação temporal de concentrações de coliformes termotolerantes nas águas superficiais dos parques urbanos amostrados.

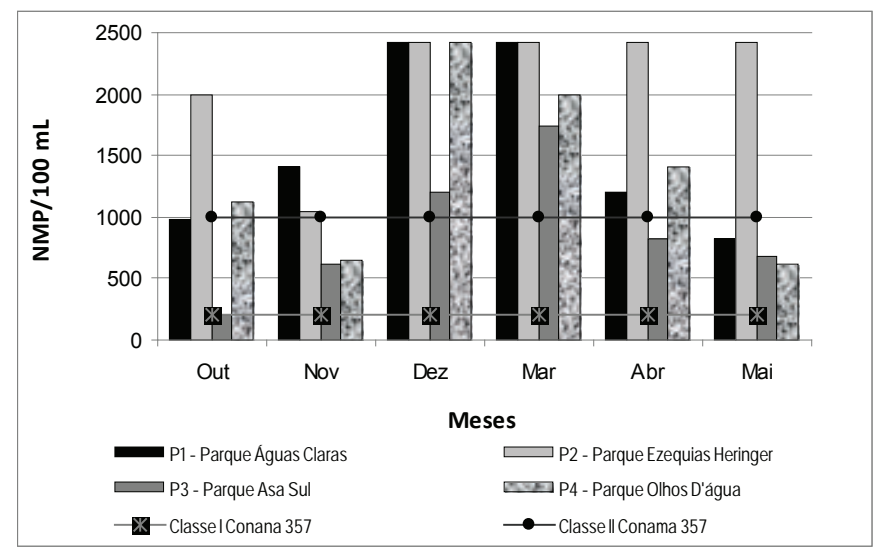

Analisando a influência da pluviosidade sobre esse fenômeno, foi possível observar que as médias de concentrações de coliformes termotolerantes em P1, P3 e P4, no período chuvoso (outubro, novembro, dezembro e março), foram superiores às obtidas no período seco (abril e maio). Já com o P2, ocorreu o inverso (figura 2).

Figura 2: Valor médio do quantitativo de coliformes termotolerantes nos períodos seco (abril e maio) e chuvoso (outubro, novembro, dezembro e março).

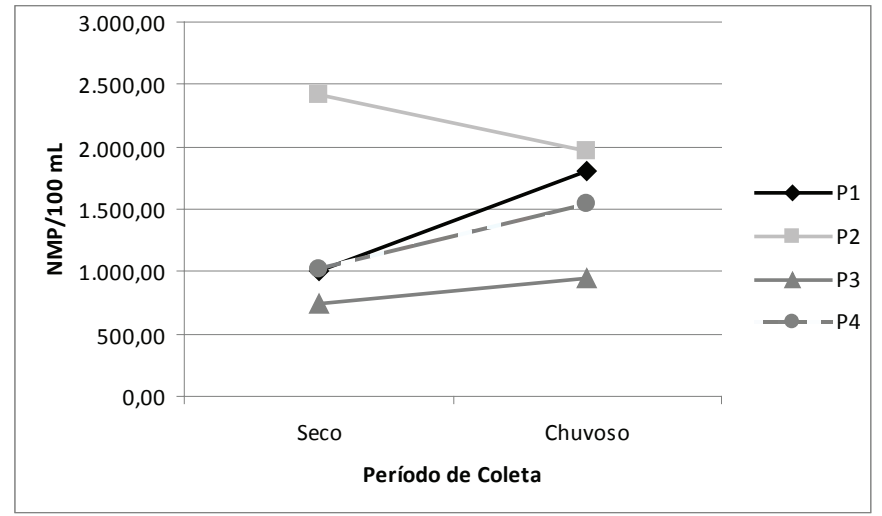

Quanto aos parâmetros físico-químicos, as temperaturas observadas nos quatro pontos amostrados não variaram significativamente nos períodos de coleta. As maiores temperaturas encontradas foram no P3 $\left(26,9^{\circ} \mathrm{C}\right)$ e as menores em P2 
$\left(17,9^{\circ} \mathrm{C}\right)$. De um modo geral, as temperaturas maiores ocorreram no período de primavera e verão, exceto no mês de dezembro (figura 3 ).

Figura 3: Variação da temperatura da água $\left({ }^{\circ} \mathrm{C}\right)$ nos pontos de amostragem ao longo dos meses pesquisados.

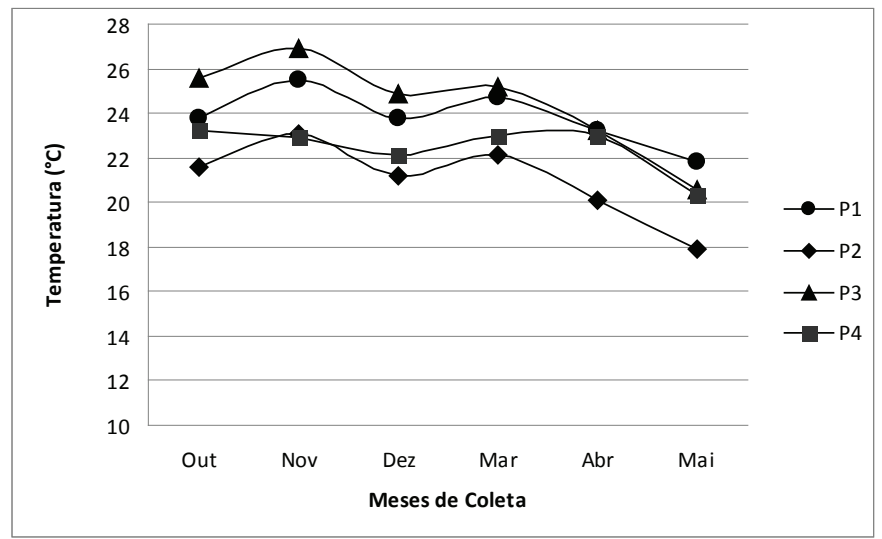

Os dados de $\mathrm{pH}$ das amostras, ao longo do período, não apresentaram grandes alterações. A maioria dos valores em P2, P3 e P4 estabilizaram-se entre 6,0 e 7,2. Já em P1, apenas no mês de dezembro, apresentou $\mathrm{pH} 6,0$, ficando abaixo durante os outros meses.

Nas análises de OD, todos os valores encontrados, ao longo dos meses pesquisados, ficaram abaixo do valor de referência da legislação, exceto em P2 que, de seis amostras, cinco apresentaram valor superior (figura 4). Em P3, as amostras tiveram valores muito inferiores variando de $1,32 \mathrm{mg} / \mathrm{L}$ a $3,98 \mathrm{mg} / \mathrm{L}$. 
Figura 4: Variação de oxigênio dissolvido (mg/L) nos pontos de amostragem ao longo dos meses. ${ }^{*}$ valor de referência da legislação.

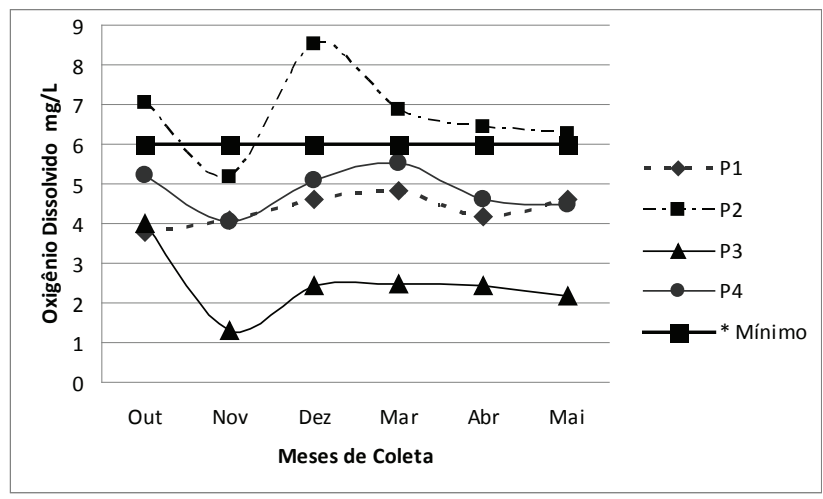

Quanto à condutividade em P2 e P4, as amostras variaram entre $90 \mu \mathrm{s} / \mathrm{cm}$ a $160 \mu \mathrm{s} / \mathrm{cm}$. Já as amostras de P1 permaneceram mais constantes e em concentrações abaixo de $33 \mu \mathrm{s} / \mathrm{cm}$. Em P3, os resultados apontam para concentrações altas entre $394 \mu \mathrm{s} / \mathrm{cm}$ a $522 \mu \mathrm{s} / \mathrm{cm}$. Em todos os parques, as maiores concentrações foram obtidas no mês de dezembro, em que foi observado o maior volume pluviométrico.

A concentração de TDS está relacionada com os valores de condutividade. Observa-se na figura 5 a mesma dinâmica temporal dos dados de condutividade, em que P3 tem as maiores concentrações e P1, os menores valores encontrados para TDS.

Figura 5: Variação de total de sais dissolvidos (mg.L $\left.\mathrm{L}^{-1}\right)$ nos pontos de amostragem.

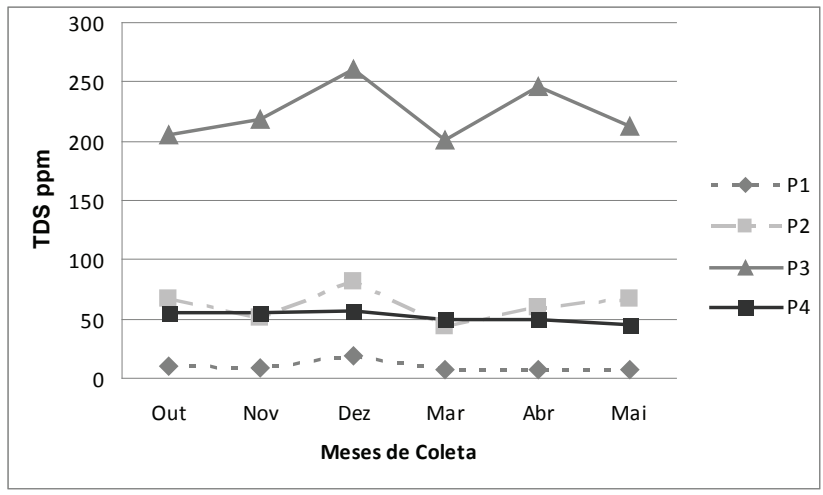


Na tabela 1, estão descritas as classes em que as águas foram classificadas de acordo com os indicadores propostos. Quanto ao indicador coliforme termotolerantes E. coli, as amostras enquadraram-se na Classe III da Resolução CONAMA 357/05, indicando que das 6 amostras, 5 (80\%) não podem exceder os valores de $>2.500 \mathrm{NMP} / 100 \mathrm{~mL}$. As águas da Classe III têm seus usos múltiplos em irrigação de culturas arbóreas, cerealíferas e forrageiras, abastecimento com tratamento convencional ou avançado, à pesca amadora, à recreação de contato secundário e à dessedentação de animais. Quanto ao indicador OD, as Classes II e III indicam respectivamente que, em qualquer amostra, os níveis não devem ser inferiores a $5 \mathrm{mg} / \mathrm{L} \mathrm{O}_{2}$ e $4 \mathrm{mg} / \mathrm{L} \mathrm{O}_{2}$, respectivamente.

Tabela 1: Enquadramento das amostras de águas pesquisadas em quatro parques do DF referentes a seis coletas nos meses de outubro a dezembro de 2009 e março a maio de 2010 de acordo com os valores de referência da Resolução CONAMA 357/05.

\begin{tabular}{ccc}
\multicolumn{2}{c}{ Indicadores } \\
\hline & OD & Coliformes Termotolerantes \\
\hline P1 & Classe III & Classe III \\
P2 & Classe II & Classe III \\
P3 & Classe III & Classe III \\
P4 & Classe III & Classe III \\
\hline
\end{tabular}

\section{Discussão}

As análises das amostras de águas superficiais dos parques pesquisados indicaram concentrações altas de coliformes termotolerantes E. coli. A presença desse tipo de bactéria indica risco potencial de doenças causadas por organismos patogênicos; essas bactérias ocorrem em quantidade na microbiota intestinal humana e de outros animais de sangue quente (REGO; BARROS; SANTOS, 2010).

A quantidade elevada de coliformes totais em todas as amostras indica contaminação por matéria orgânica, o que é natural em áreas verdes. O parâmetro microbiológico coliformes termotolerantes foi grandemente influenciado pela sazonalidade, que fez com que o escoamento superficial das chuvas aumentasse 
consideravelmente os níveis de contaminação, principalmente nos parques Águas Claras, Asa Sul e Olhos D’água. Mesmo assim, nos períodos secos, a poluição de origem fecal observada também foi considerada alta.

Os resultados apresentados para o quantitativo de coliformes termotolerantes nas amostras do Parque Ezechias Heringer sugerem que, além das chuvas, há uma contribuição pontual de poluição. Esse parque enfrenta problemas de ocupação irregular e provável lançamento clandestino de esgoto doméstico.

No Parque Águas Claras, a atividade construtiva e a falta de infraestrutura, como drenagem urbana e lixeiras, são as principais fontes de poluição. Além disso, foi observada a presença de muitas fossas em empreendimentos imobiliários em construção. O Parque enfrenta ainda grandes problemas de erosão e assoreamento dos rios com grande concentração de resíduos da construção civil.

Quanto ao Parque Asa Sul, a falta de declividade pode ter contribuído para as menores concentrações de coliformes termotolerantes, ou ainda fatores físico-químicos. Ele também enfrenta problemas de invasões, porém estas não são fixas quanto as do Parque Ezechias Heringer. O Parque Olhos D’água sofre com invasões e lançamento clandestino de lixo e resíduos domésticos.

Brito et al. (2008), em análise situacional de parques do Distrito Federal, constataram que, embora um pequeno número de parques esteja em boas situações, a grande maioria só existe no papel ou enfrenta problemas como invasão, falta de cercamento, ausência de fiscalização, depredação ambiental e especulação imobiliária.

Outros autores em pesquisas com água em ambientes urbanos também encontraram situações de irregularidades alarmantes, tanto para parâmetros microbiológicos quanto físico-químicos. Lemos, Ferreira Neto e Dias (2010) encontraram variação na qualidade bacteriológica da água comprometendo a Lagoa do Apodi, no Rio Grande do Norte, principalmente logo após o período das chuvas. No riacho do Piauí, Arapiraca-AL, os resultados mostraram que o rio encontrava-se totalmente contaminado por coliformes fecais. A nascente foi enquadrada 
como Classe II, embora todo o rio dentro do perímetro urbano é considerado como de Classe IV (DORNELLAS; CAMPOS, 2008).

Em análise do Córrego Campestre em Lins-SP, Cuebas e Carvalho (2009) demonstraram que o córrego apresenta um elevado grau de degradação, devido à grande quantidade de sedimentos, coliformes e nutrientes.

Em relação às temperaturas, as diferenças quanto ao período chuvoso e seco foram pequenas. Diversos fatores podem afetar a temperatura da água: estação do ano, altitude, horário do dia, profundidade do local e presença de vegetação. Para Tucci et al. (2004), a temperatura pode ser considerada a característica mais importante do meio aquático, pois caracteriza grande parte dos outros parâmetros físicos da água, tais como a densidade, viscosidade, pressão de vapor e solubilidade dos gases dissolvidos. Tanto a temperatura da água quanto a temperatura do ar são de extrema importância para os sistemas aquáticos e terrestres, pois os organismos possuem diferentes reações às mudanças desse fator. Portanto, seu aumento devido à poluição térmica causa aceleração dos mecanismos de respiração, nutrição, reprodução e movimentação; caso a temperatura abaixe, o efeito é contrário (SCHIAVETTI, 2007).

É importante destacar que a introdução de oxigênio dissolvido em águas naturais depende da taxa de aeração superficial; sendo assim, rios com cascatas, turbilionamento causados por declives acentuados e correnteza, podem apresentar altas taxas de oxigênio dissolvido (CETESB, 2010). O Córrego Guará e Talveque, localizados respectivamente nos parques Ezequias Heringer e Olhos D'água, apresentaram maior autodepuração devido às características de ambientes hídricos lóticas. Já nos parques Asa Sul e Águas Claras, a característica é de ambientes hídricos lênticos.

De acordo com Agência de Proteção Ambiental dos Estados Unidos (EPA), as faixas de concentração de oxigênio dissolvido com as respectivas comunidades aquáticas que podem suportar tais níveis de oxigênio dissolvido são: de 0 a $2 \mathrm{mg} \mathrm{L}$, insuficientes para manter a vida aquática; de 2 a $4 \mathrm{mg} / \mathrm{L}$, somente poucas espécies de peixes podem sobreviver; de 4 a $7 \mathrm{mg} / \mathrm{L}$, é aceitável para peixes de águas quentes; e de 7 a 11 mg/L, é ideal para peixes de águas frias (SILVA; JARDIM, 2006). 
Portanto, pode-se constatar que no período observado, as águas do Parque Asa Sul apresentaram oxigênio dissolvido insuficiente para a manutenção da vida aeróbia, indicando estar em um possível processo de eutrofização. A presença de bactérias termotolerantes em suas águas é justificável, pois essas bactérias são aeróbias facultativas. Os corpos de água corrente possuem uma capacidade natural de autodepuração. A matéria orgânica endógena e os resíduos biodegradáveis, quando lançados no rio, são oxidados pela ação de microrganismos, especialmente bactérias (SIQUEIRA, 1998).

Em pesquisa geoquímica das águas da bacia hidrográfica do Rio Descoberto-DF, foram encontradas concentrações elevadas de diversos parâmetros físico-químicos, principalmente próximos às regiões urbanas e agrícolas (CARMO; BOAVENTURA, 2005). De acordo com a pesquisa, as águas estudadas estariam enquadradas na Classe IV, destinada à navegação e harmonia paisagística. Viera et al. (2006) pesquisaram a qualidade da água de lagos e lagoas do Parque Urbano Águas Branca-SP, quanto aos parâmetros físico-químicos, e encontraram um grande aporte de matéria orgânica com indício de franco processo de eutrofização.

A condutividade elétrica indica a quantidade de sais existentes na coluna d'água e, portanto, representa uma medida indireta da concentração de poluentes (LIBÂNIO, 2005). De acordo com Silva et al., (2007), quanto maior for a quantidade de íons dissolvidos, maior será a condutividade elétrica da água. Em águas continentais, os íons diretamente responsáveis pelos valores da condutividade são, entre outros, o cálcio, o magnésio, o potássio, o sódio, carbonatos, carbonetos, sulfatos e cloretos.

Apesar da legislação não ter parâmetros referentes à condutividade, a CETESB indica que valores acima de $100 \mu \mathrm{s} / \mathrm{cm}$ indicam ambientes impactados.

Nas áreas estudadas, notou-se claramente a relação entre condutividade e TDS que representa um total de sais (minerais, sais ou metais) que estão dissolvidos em um dado volume de água. Quanto maior o nível do TDS na água, maior a probabilidade de contaminadores (ARAÚJO; PINTO FILHO, 2010). 
A qualidade da água está relacionada ao tipo de uso e deve ser mantido um constante monitoramento de suas qualidades físicas, químicas e biológicas a fim de impedir danos ao sistema aquático e, em última análise, à saúde humana (SARDINHA et al. 2008).

Vale ressaltar que a qualidade da água funciona como um meio de diagnóstico do estado de conservação ambiental; mediante sua análise, é possível determinar o grau de erosão do solo, lançamentos orgânicos, poluição dos esgotos e a poluição atmosférica (BEZERRA, 2008).

Outro ponto importante é que parques urbanos são elementos fundamentais para o equilíbrio ambiental e convívio social em grandes cidades, sendo necessários estudos voltados para a integração da área protegida com as áreas urbanizadas (MAZZEI; COLESANTE; SANTOS, 2007).

Portanto, fica evidente que apenas a criação e a delimitação de uma área de Unidade de Conservação não garantem a qualidade das águas e a proteção das comunidades biológicas.

\section{Conclusão}

A partir dos resultados encontrados, podemos concluir que as águas dos parques pesquisados encontram-se contaminadas por coliformes termotolerantes E. coli. O parque que apresentou maiores quantitativos de bactérias do grupo coliformes foi o Parque Ezechias Heringer, seguido, respectivamente, pelos parques Águas Claras, Olhos D’água e Asa Sul.

A caracterização dos pontos pesquisados ao longo dos meses, em sua maioria, se enquadrou na Classe III. O indicador microbiológico foi mais expressivo na avaliação da qualidade das águas em estudo e apresentou maior influência da sazonalidade. 
Sugere-se a realização de estudos para determinar as concentrações de nutrientes no Parque Asa Sul, já que, nesse ambiente, foram determinados altos valores para condutividade, TDS e baixas concentrações de OD.

Para manter a qualidade e proteção das comunidades biológicas, são necessários investimentos, fiscalizações e planos de manejo para mitigar impactos antrópicos.

\section{Microbiological and physicochemical characterization of superficial waters in urban parks in the Federal District}

\section{Abstract}

Aquatic environments located in urban centers suffer intense pressures from human activities affecting their quality. The creation of urban parks is one of the main strategies used to minimize these impacts and to achieve protection and conservation of natural environments. This study aims to characterize both microbiological and physicochemical properties of waters located in four urban parks in the DF, which are part of the basin of Lake Paranoa unit. The samples were collected monthly for the period October to December 2009 and March-May 2010. Results show that in three parks (Águas Claras, Asa Sul and Olhos D'água) fecal coliform concentrations increased in the months from October to December (between 200 and 2,419.6 MPN/100mL) and decreasing values in March-May (from 344.60 to $2,419.6 \mathrm{MPN} / 100 \mathrm{~mL}$ ). In the Ezechias Heringer Park (Guará) from december the amount of this indicator remained constant with value $>2419.6 \mathrm{MPN} / 100 \mathrm{ml}$. The physicochemical parameters showed no significant changes over the months, but were important in assessing the water quality of the Asa Sul Park

Keywords: Water quality. Pollution. Urbanization. 


\section{Referências}

ARAÚJO, J. B. S.; PINTO FILHO, J. L. Identificação de fontes poluidoras de metais pesados nos solos da bacia hidrográfica do Rio Apodi-Mossoró, RN, na área urbana. Revista Verde, Mossoró, RN, v. 5, n. 2, p. 80-94, 2010.

APHA, AWWA, WEF. Standard methods for the examination of water and wastewater. 19. ed. Washington, DC: APHA, 1995.

BEZERRA, I. S. O; MENDONÇA, L. A. R; FRISCHKORN, H. Autodepuração de cursos d’água: um programa de modelagem Streeter Phelps com calibração automática e correção de anaerobiose. Revista Escola de Minas, Ouro Preto, v. 61, n. 2, p. 249-255, 2008.

BRITO, D. Q. et al. Análise situacional de cinco parques urbanos de Brasília: áreas estratégicas para a conservação de cerrado no meio urbano. In: SIMPÓSIO NACIONAL CERRADO, 9., Brasília. Anais... Brasília, 2008.

BOLLMAN, H. A. Relação da densidade populacional sobre variáveis de qualidade físico: química das águas superficiais em microbacias hidrográficas urbanas sem cobertura sanitária em Porto Alegre. 2003. Tese (Doutorado)Universidade Rio Grande do Sul, Porto Alegre, 2003.

CÂMARA LEGISLATIVA DO DISTRITO FEDERAL. Lei complementar $\mathbf{n}^{\circ} \mathbf{2 6 5}$, de 14 de dezembro de 1999. Dispõe sobre a criação de Parques Ecológicos e de Uso Múltiplo no Distrito Federal. Disponível em: <http://www.cl.df.gov.br/Legislacao/ buscarLei-1081!buscarLei.action>. Acesso em: 06 maio 2010.

CARMO, M. S; BOAVENTURA, G. R. Geoquímica das águas da bacia hidrográfica do Rio Descoberto, Brasília, DF. Química Nova, São Paulo, v. 28, n. 4, p. 565-574, 2005. doi:10.1590/S0100-40422005000400002.

CETESB. Variáveis de qualidade das águas. Disponível em: <http://www.cetesb. sp.gov.br/Agua/rios/variaveis.asp>. Acesso em: 06 maio 2010.

CUEBAS, L. P; CARVALHO, S. L. Avaliação da qualidade da água na microbacia do Córrego Campestre no Município de Lins, SP. Holos Environment, Rio Claro, v. 9, n. 1, p. 14-30, 2009.

CUNHA, A. C. Levantamento de parâmetros físico-químicos e hidráulicos para a avaliação da qualidade da água em escoamentos naturais: desenvolvimento do distrito industrial/AP na Bacia do Rio Matapi. Relatório Anual. Macapá: CNPq/ IEPA/Gerco, 2001. 
DREW, D. Processos interativos homem-meio ambiente. 4. ed. Rio de Janeiro: Bertrand Brasil, 1998.

DORNELLAS, P. C; CAMPOS, H. L. Efeitos do crescimento urbano na qualidade das águas do Riacho Piauí, Arapiraca-AL. Revista de Geografia, Recife, v. 25, n. 2, p. 113-123, 2008.

GOULART, M. D.; CALLISTO, M. Bioindicadores de qualidade de água como ferramenta em estudos de impacto ambiental. Revista FAPAM, Pará de Minas, v. 2, n. 1, p. 1-9, 2003.

GOMES, J. B. V. et al. Análises de componentes principais de atributos físicos, químicos e mineralógicos do solo do bioma cerrado. Revista Brasileira de Ciência do Solo, Viçosa, v. 28, n. 1, p. 137-153, 2004. doi:10.1590/S010006832004000100014.

INSTITUTO DO MEIO AMBIENTE E DOS RECURSOS HIDRICOS DO DISTRITO FERDERAL (IBRAM). Histórico de parque do Distrito Federal. Disponível em: <http://www.ibram.df.gov.br/>. Acesso em: 15 mar. 2010.

IDEXX LABORATORIES (IDEXX). One idexx drive. Disponível em: <http:// www.idexx.com.>. Acesso em: 01 mar. 2009.

LEMOS, M; FERRERIA NETO, M; DIAS, N. S. Sazonalidade e variabilidade espacial da qualidade da água na Lagoa do Apodi, RN. Revista Brasileira de Engenharia Agrícola e Ambiental, Campina Grande, v. 14, n. 2, p. 155-164, 2010. doi:10.1590/S1415-43662010000200006.

LIBÂNIO, M. Fundamentos de qualidade e tratamento de água. Campinas: Átomo, 2005.

LIBANO, P. A. C. A Implementação da política nacional de recursos hídricos e sua interface com aspectos de qualidade de água: implicações da regulação de recursos hídricos sobre o setor de saneamento e no controle da poluição hídrica. Belo Horizonte. 2004. Tese (Doutorado)-Programa de Pós-Graduação em Saneamento, Meio Ambiente e Recursos Hídricos da UFMG, Belo Horizonte, 2004.

LIMA, J. E. F. W.; SILVA, E. M. Recursos hídricos do bioma cerrado importância e situação. In: SANO, S.M.; ALMEIDA, S.P. (Ed.). Cerrado: ecologia e flora. Planaltina, DF: Embrapa Cerrados, 2008. p. 91-106.

MATHEUS, C. E. Manual de análise limnológicas. São Carlos: USP, 1995. 62 p. 
MAZZEI, K; COLESANTE, M. T. M; SANTOS, D. G. Áreas verdes urbanas, espaços livres para o lazer. Sociedade \& Natureza, Uberlândia, MG, v. 19, n. 1, p. 33-43, 2007.

MOREIRA, R.C. A; BOAVENTURA, G.R. Referência geoquímica regional para a interpretação das concentrações de elementos químicos nos sedimentos da Bacia do Lago Paranoá, DF. Química Nova, São Paulo, v. 26, n. 6, p. 812-820, 2003. doi:10.1590/S0100-40422003000600006.

PAZ, V. P. S; TEODORO, R. E. F; MENDONÇA, F.C. Recursos hídricos, agricultura irrigada e meio ambiente. Revista Brasileira Engenharia Agrícola Ambiental, Campina Grande, PB, v. 4, n. 3, p. 465-473, 2000. doi:10.1590/S141543662000000300025.

REGO, N. A. C; BARROS, S. R; SANTOS, J.W. B. Avaliação espaço-temporal da concentração de coliformes termotolerantes na lagoa encantada, Ilhéus, BA. Revista Eletrônica do Prodema, Ilheus, BA, v. 4, n. 1, p. 55-69, 2010.

RIBEIRO, J. F; SCHIAVINI, I. Recuperação de matas de galeria: integração entre a oferta ambiental e a biologia das espécies. In: RIBEIRO, J. F. (Ed.) Cerrado: matas de galeria. Brasília: Embrapa, 1998. p. 137-153.

RONDON LIMA, E. B. N. Modelação integrada para gestão da qualidade da água na bacia do Rio Cuiabá. Rio de Janeiro. 2001. Tese (Doutorado)-Universidade do Rio de Janeiro, Rio de Janeiro, 2001.

SARDINHA, D. S. et al. Avaliação da qualidade da água e autodepuração do Ribeirão do Meio, Leme, SP. Engenharia Sanitária e Ambiental, Rio de Janeiro, v. 13, p. 329-338, 2008. doi:10.1590/S1413-41522008000300013.

SIQUEIRA, E. Q. O modelo qual2e na modelação de OD no rio Meia Ponte, Estado de Goiás - Brasil. In: CONGRESSO INTERAMERICANO DE INGENIERIA SANITARIA E AMBIENTAL. Anais... Asociación Peruana de Ingenieria Sanitaria y Ambiental; AIDIS. Gestión ambiental en el siglo XXI. Lima, APIS, 1998. Disponível em: <http://www.bvsde.paho.org/ bvsaidis/caliagua/peru/bracca009. pdf $>$. Acesso em: 05 jun. 2010.

STRIEDER, M. N. et al. Medidas biológicas e índices de qualidade da água de uma microbacia com poluição urbana e de curtumes no sul do Brasil. Acta Biologica Leopondensia, v. 28, n. 1, p. 17-24, 2006. 
SCHIAVETTI, A. Informação ambiental sobre os parâmetros do kit de análise de água, 2007. Disponível em: <http://educar.sc.usp.br/biologia/ textos/m_a_txt9. html>. Acesso em: 19 maio 2010.

SILVA, G. S; JARDIM, W. F. Um novo índice de qualidade das águas para proteção de vida aquática aplicado ao Rio Atibaia, região de Campinas, Paulínia, SP. Química Nova, São Paulo, v. 29, n. 4, p. 689-694, 2006. doi:10.1590/S010040422006000400012.

SILVA, D. F; SOUSA, F. A. S; KAYANO, M. T. Avaliação dos impactos da poluição nos recursos hídricos da bacia do Rio Mundaú (AL e PE). Revista de Geografia, Recife, v. 24, n. 3, p. 210-223, 2007.

TUCCI, C. E. M; HESPANHOL, I; CORDEIRO NETO, O. M. Cenário da gestão da água no Brasil: uma contribuição para a visão mundial da água. Revista Brasileira de Recursos Hídricos, Porto Alegre, v. 5, n. 3, p. 31-43, 2000.

TUCCI, C. E. M. Hidrologia: ciência e aplicação, 3. ed. Porto Alegre: UFRGS/ ABRH, 2004.

VIEIRA, M. S; MOURA, M. A. M; GIL, F. G. Qualidade da água de lagos e nascentes do Parque Dr. "Fernando Costa” (Água Branca), São Paulo, SP. Arquivos do Instituto Biológico, São Paulo, v. 73, n. 4, p. 475-483, 2006. 